\title{
Feasibility study of a novel acquisition technique of cardiac cine magnetic resonance imaging in patients with atrial fibrillatio
}

\author{
Jian Cao ${ }^{1 *}$, Yining Wang ${ }^{1}$, Lingyan Kong ${ }^{1}$, Lu Lin ${ }^{1}$, Yan $\mathrm{Yi}^{1}$, Jing An², Tianjing Zhang ${ }^{2}$, Zhengyu Jin ${ }^{1}$ \\ From 18th Annual SCMR Scientific Sessions \\ Nice, France. 4-7 February 2015
}

\section{Background}

For patients with arrhythmia, conventional segmented steady-state free precession sequence (CINE-SSFP) methods may result in poor image quality. Real-time cine could avoid those limitations, however poor spatial and temporal resolutions of conventional sequences have prevented its routine application. Recently a newly developed compressed sensing (CS) cine shows the ability to provide both spatial and temporal resolution in real time. The purpose of this study is to assess its performance in patients with atrial fibrillation.

\section{Methods}

CMR was performed at 3.0T system (MAGNETOM Skyra, Siemens Healthcare, Erlangen, Germany). The examinations included the following sequences (Table 1): (1), conventional segmented SSFP (iPAT3) (GRAPPA accel factor 3, temporal resolution, $45.6 \mathrm{~ms}$; voxel size, $1.6 \times 1.6 \times 8.0 \mathrm{~mm} 3)$; (2), conventional realtime (TPAT3) (TGRAPPA accel factor 3, temporal resoluion $49.9 \mathrm{~ms}$; voxel size $2.8 \times 2.8 \times 8.0 \mathrm{~mm} 3)$; (3), segmented CS (SPARSE11.5) (accel factor 11.5, temporal resolution, $41.7 \mathrm{~ms}$; voxel size $2.0 \times 2.0 \times 8.0 \mathrm{~mm} 3$ ); (4), real-time CS (SPARSE9.3) (accel factor 9.3, TR, $17 \mathrm{~ms}$; voxel size, $2.0 \times 2.0 \times 8.0 \mathrm{~mm} 3$ ). Stacks of short-axis (SAX) cines were acquired covering both ventricles. For every subject, three SAX slices (base, mild and apex) of each sequence were selected and reviewed in the random order. Image quality scoring was performed by two experts using 5-point score (1-5 from poor to good).

\section{Results}

CMR examinations of 6 patients ( $46 \pm 18$ years, 1 male) with AF were completed successfully. Short axis slice acquisition times were shorter for TPAT3 $(0.8 \pm 0.1 \mathrm{~s})$ than iPAT3 $(6.0 \pm 0.0 \mathrm{~s})$, SPARSE11.5 (1.6 $\pm 0.2 \mathrm{~s})$ and SPARSE9.3 (3.1 $\pm 0.5 \mathrm{~s}$ )(Table 1). But on overall image quality, the SPARSE9.3 technique was best, which was superior to iPAT3, TPAT3 and SPARSE11.5 (Table 1), neither standard segmented SSFP nor standard real-time sequence could have diagnostic quality. And the image quality of base-segments were worse than mild and apex segments because of flow artifacts (Fig 1).

\section{Conclusions}

Our small sample research indicates that for patients with arrhythmia, the conventional SSFP and real-time

Table 1 Comparisons of scan time and image quality

\begin{tabular}{ccc}
\hline Sequence & $\begin{array}{c}\text { Scan time (sec/ } \\
\text { slice) }\end{array}$ & $\begin{array}{c}\text { Overall image quality (1-5 from poor to } \\
\text { good) }\end{array}$ \\
\hline iPAT3 & $6.0 \pm 0.0$ & $3.7 \pm 0.5$ (base) \\
\cline { 3 - 3 } & & $3.8 \pm 1.0$ (mild) \\
\cline { 3 - 3 } & & $3.8 \pm 0.7$ (apex) \\
\hline TPAT3 & $0.8 \pm 0.1$ & $3.6 \pm 0.5$ (base) \\
\cline { 3 - 3 } & & $3.6 \pm 0.5$ (mild) \\
\cline { 3 - 3 } & & $3.6 \pm 0.5$ (apex) \\
\hline SPARSE11.5 & $1.6 \pm 0.2$ & $4.1 \pm 0.8($ base) \\
& & $4.2 \pm 0.4$ (mild) \\
\cline { 3 - 3 } & & $4.2 \pm 0.8$ (apex) \\
\hline SPARSE9.3 & $3.1 \pm 0.5$ & $4.2 \pm 0.4($ base) \\
\cline { 2 - 3 } & & $4.6 \pm 0.5$ (mild) \\
\cline { 2 - 3 } & & $4.8 \pm 0.4$ (apex) \\
\hline
\end{tabular}

${ }^{1}$ Radiology, Peking Union Medical College Hospital, Beijing, China Full list of author information is available at the end of the article 


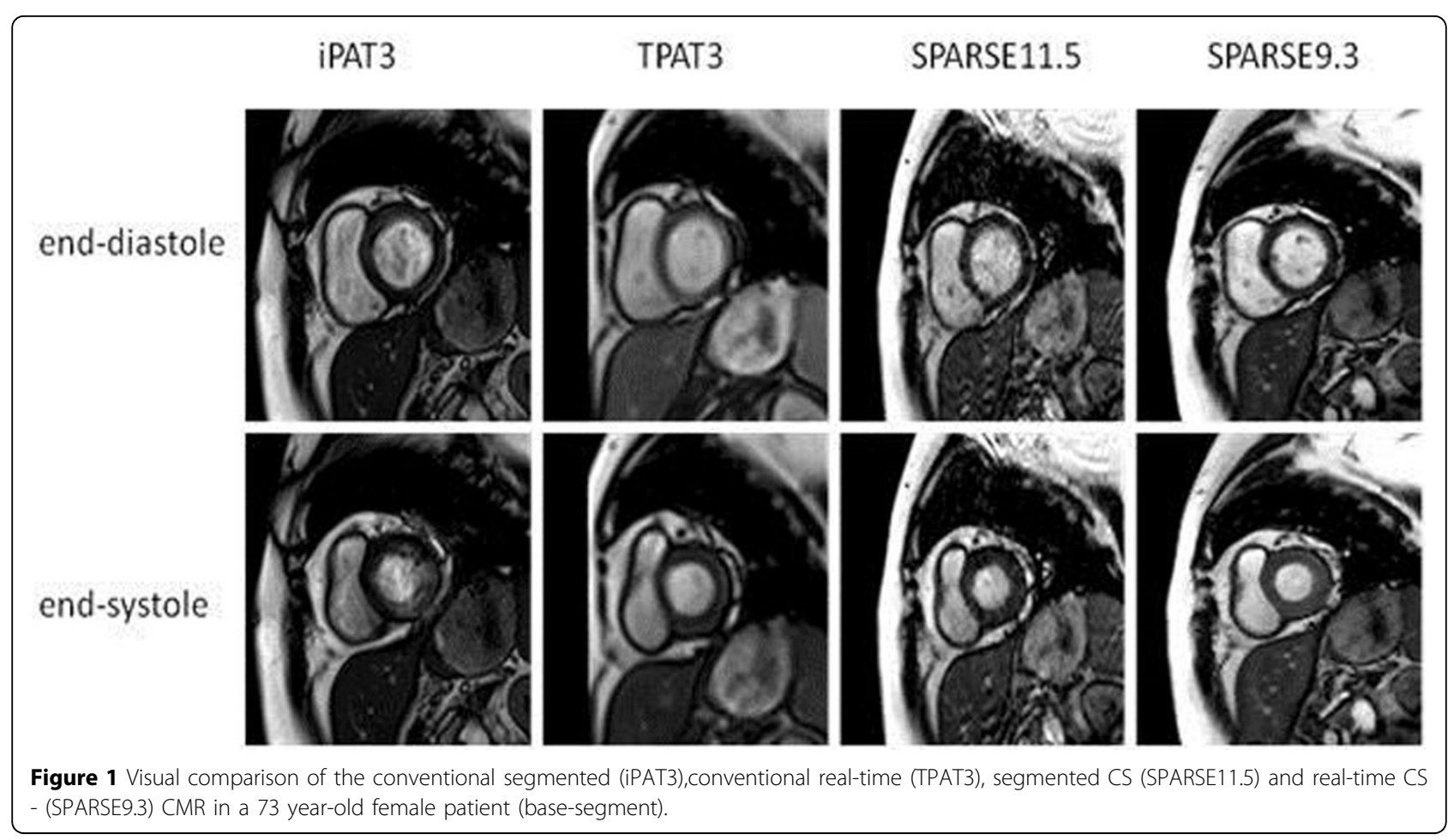

sequences could not fulfill the clinical requirements. With the application of CS cine sequence, we could acquire high-quality cardiac cine images which greatly reduce the scan time. In future, it could be applied in more clinical patients.

\section{Funding}

N/A.

\section{Authors' details}

${ }^{1}$ Radiology, Peking Union Medical College Hospital, Beijing, China. ${ }^{2}$ MR

Collaborations NE Asia, Siemens Healthcare, Beijing, China.

Published: 3 February 2015

doi:10.1186/1532-429X-17-S1-T12

Cite this article as: Cao et al: Feasibility study of a novel acquisition technique of cardiac cine magnetic resonance imaging in patients with atrial fibrillatio. Journal of Cardiovascular Magnetic Resonance 201517 (Suppl 1):T12.
Submit your next manuscript to BioMed Central and take full advantage of:

- Convenient online submission

- Thorough peer review

- No space constraints or color figure charges

- Immediate publication on acceptance

- Inclusion in PubMed, CAS, Scopus and Google Scholar

- Research which is freely available for redistribution 